\title{
Preface to the Paperback Edition
}

Since the first publication of Law in Culture and Society in 1969, there has been a virtual revolution in thinking about law by practitioners in sister disciplines. The story of what has happened is written about elsewhere in long and protracted form. Here I will merely note that movements made the difference, in the direction of scholarship at least. The Development Movement sought to democratize the third world by exporting Europe-American legal education and legal codes and statutes, an inexpensive kind of development which is currently being renewed by efforts in Eastern Europe. The Law and Society Movement made a niche for law and society scholars who were marginal or who did not fit in law schools, political science, sociology, psychology, criminology, history or anthropology departments-people who saw in law the tools for research and reform related to poverty, racism, and sexism, for example. The Critical Legal Studies Movement is a progressive examination of the assumptions of American law and legal education that revealed a law that was more political than neutral, results that might not surprise the downtrodden. Law and Economics, Chicago style, was a reactionary move that loosely paralleled the Reagan Revolution. For scholars there was excitement, for example, in discoveries of law as a vehicle for cultural transmissions or legal imperialisms. When the same patterns were found on home ground there was a crisis of contradictions. The law was not neutral as supposed.

Finally, there has come a recognition of dead-ends. Law and Society is increasingly encapsulated, and more and more replicating that which many sought to escape-boundary controls. Critical Legal Studies is often caught in disembodied literatures and narrative techniques that focus on more discourse-based positions to the exclusion of other factors involved in the 
creation of social beings.Thus, whether about the everyday or the abstract, the original power of the "new thinking" wanes just as new thinking about law is taking hold in places like Italy or France.

From the perspective of anthropology as a discipline the change was cumulative, not dramatic, because intellectually the anthropology of law gave to the movements perhaps more than we received. "Our" terrain-the nonwestern other-our approaches and methods such as participant observation, and what we had learned about social and cultural processes through ethnography, filtered into other disciplines. Notions of critique and comparison, culture and local knowledge, and the various ideas about pluralism and perception had now moved horizontally into sister disciplines, albeit in altered forms.

But there were also subtle changes during this period. Anthropologists learned about the power of law and in law, something more obvious to lawyers than anthropologists. The ethnographic study of law in other cultures, a study that had already yielded a small number of classic ethnographies, continued to be small in number while distinguished anthropologists chose to write ethnographies of law in the United States. New work in Africa diminished and a few outstanding monographs began to appear in Mexico, Brazil, Tibet, Indonesia and the Pacific and elsewhere.

In 1969, dispute resolution was a subject matter that engaged empirically-grounded ethnographers concerned with what law does instead of what law is. In 1996, dispute resolution is an industry that has penetrated the neighborhoods, the schools, the prisons, the corporations, the NAFTA and the GATT, and once again, third world countries dealing with conflicts accompanying decolonization. Throughout this period mainstream legal thought has been severely shaken.

In 1969, anthropologists were treated with disdain by fellow social scientists for examining the everyday in law life because for them real social dramas were elsewhere-in the prisons, in the judgeships, in the streets, or in jurisprudential exploration. By 1996, the anthropological domain had been run over by our fellow social scientists with interest in everyday life and the part played by law in communities. Legal pluralism and dispute resolution interested activists and juridical planners, as well as "identity construction." Now, it is more difficult to tell who is an anthropologist and who is not, or indeed to respond to assertions that by the late 1990s "there are more anthropologists of law who are lawyers than anthropologists," but it is clear that there is a continued interest in anthropologically-rooted studies concerned with the less visible face of law and the view from below.

Since 1969, the view from below has expanded upward and outward. Anthropologists had consistently underestimated the role of legal ideologies in the construction or deconstruction of culture writ large. Legal ideologies such as the harmony law model were used as techniques of pacification among colonized peoples, in nation-states and as well in the international 
arena. Yet, the effort to understand the political economy of legal models as adumbrated in our volume in papers on legal styles, historical changes in the law of nation-states, colonialism and the politics of law, and even the Bohannan-Gluckman controversy over folk and analytic categories was more political in nature than either of them might admit.

Arguments over the notion of autonomous systems were embedded in boundary concerns. Could there be a legal system that operated independent of its environment? In our volume, indigenous systems of law are described ethnographically as part of the indigenous culture and society. Years later we were to realize that the study of colonialisms shifted our entire perspective as to what constituted indigenous culture and society. In 1996, we include legal transplants, missionary justice, AID programs, economic globalization as part of the local ethnographic picture. We were correct to be uneasy about drawing boundaries in 1969; boundaries are continually erased as knowledge and political domains shift.

In my first Preface, I indicated that the conference which produced the volume had been tumultuous. Clearly, the intellectual issues about ethnography and interpretation were all there simmering-whose categories do we use, the Other or the West? What is ethnography? When is ethnography ethnographic? Should we standardize data collection? When do we include colonials and missionaries? Do we recognize Pueblo law as a result of forces of conquest?

The political differences between us were there, but they were unmentionable. Only later are we coming to realize the tightrope that many ethnographers were walking between advocacy and objectivity, between generalization and interpretation. A rereading of these essays from the vantage of the 1990s with an improved understanding of the impact of colonialism, the Cold War, and the competition for world resources, suggests the lasting worth of these detailed studies which span generations, disciplines, nationalities, and four continents.

Laura Nader

Berkeley, California

August 1996 